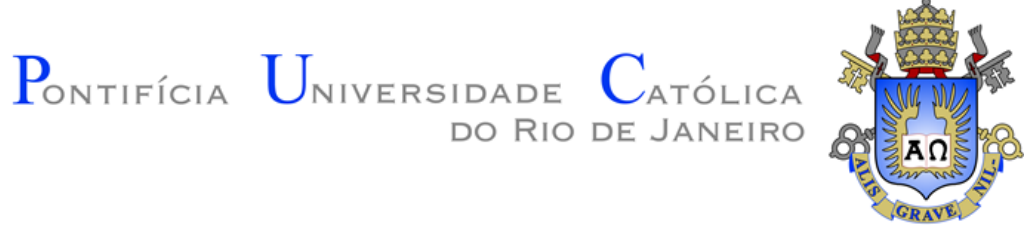

Fredy Alvaro Elorrieta Agramonte

\title{
Aplicação do método dos elementos discretos na modelagem do mecanismo de tombamento bloco-flexural em taludes rochosos
}

\section{Dissertação de Mestrado}

Dissertação apresentada como requisito parcial para obtenção do grau de Mestre pelo Programa de Pósgraduação em Engenharia Civil do Departamento de Engenharia Civil da PUC-Rio.

Orientador: Prof. Euripedes do Amaral Vargas Jr. Co-orientador: Prof. Rodrigo Pelucci de Figueiredo 


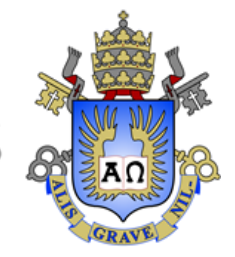

Fredy Alvaro Elorrieta Agramonte

\section{Aplicação do método dos elementos discretos na modelagem do mecanismo de tombamento bloco-flexural em taludes rochosos}

Dissertação apresentada como requisito parcial para obtenção do grau de Mestre pelo Programa de PósGraduação em Engenharia Civil do Departamento de Engenharia Civil do Centro Técnico Científico da PUC-Rio. Aprovada pela Comissão Examinadora abaixo assinada.

Prof. Euripedes do Amaral Vargas Jr Orientador Departamento de Engenharia Civil - PUC-Rio

Prof. Sérgio Augusto Barreto da Fontoura Departamento de Engenharia Civil - PUC-Rio

Prof. Emílio Velloso Barroso Universidade Federal do Rio de Janeiro

Prof. José Eugenio Leal Coordenador Setorial do Centro

Técnico Científico - PUC-Rio

Rio de Janeiro, 24 de Junho de 2014 
Todos os direitos reservados. É proibida a reprodução total ou parcial do trabalho sem a autorização da universidade, do autor e do orientador.

\section{Fredy Alvaro Elorrieta Agramonte}

Graduou-se em Engenharia de Minas, pela Universidad Nacional San Antonio Abad del Cusco - Perú. Trabalhou como engenheiro de minas em operações subterrâneas; em 2012 iniciou o curso de mestrado em Engenharia Civil na PUC-Rio, na área de geotecnia, atuando na linha de pesquisa em Mecânica das Rochas

Ficha Catalográfica

Elorrieta Agramonte, Fredy Alvaro

Aplicação do método dos elementos discretos na modelagem do mecanismo de tombamento blocoflexural em taludes rochosos/ Fredy Alvaro Elorrieta Agramonte; orientador: Euripedes do Amaral Vargas Jr.; co-orientador: Rodrigo Pelucci de Figueiredo. Rio de Janeiro PUC, Departamento de Engenharia Civil, 2014.

v., 107 f,; il. ; 29,7 cm

1. Dissertação (mestrado) - Pontifícia Universidade Católica do Rio de Janeiro, Departamento de Engenharia Civil.

Inclui referências bibliográficas.

1. Engenharia Civil - Teses. 2. Método dos Elementos Discretos 3.Estabilidade de taludes; 4 . Tombamento bloco-flexural; 5 . Mecânica das Rochas. 6. Resistência à tração das rochas. I. Vargas, Eurípedes Jr. II. Figuiredo, Rodrigo P. III. Pontifícia Universidade Católica do Rio de Janeiro. Departamento de Engenharia Civil. IV. Título. 


\section{Agradecimentos}

A meus pais e meu irmão pela imensa motivação, compreensão, amor; e por me influenciar positivamente na escolha dos meus paradigmas.

À Capes e à PUC-Rio, pelos auxílios concedidos, sem os quais este trabalho não poderia ter sido realizado.

Ao meu orientador e co-orientador pelo apoio e orientação outorgados.

A Luis, pela sua amizade e apoio na realização desta dissertação. 


\section{Resumo}

Elorrieta Agramonte, Fredy Alvaro; Vargas, Euripedes Jr.; Figueiredo, Rodrigo Pelucci. Aplicação do método dos elementos discretos na modelagem do mecanismo de tombamento bloco-flexural em taludes rochosos. Rio de Janeiro, 2014. 106p. Dissertação de Mestrado Departamento de Engenharia Civil, Pontifícia Universidade Católica do Rio de Janeiro.

Em um maciço rochoso, as fraturas apresentam-se de forma irregular e descontínua. A complexidade na distribuição espacial destas descontinuidades faz com que o mecanismo de ruptura por tombamento ocorra mais frequentemente por uma combinação de dois tipos de fenômenos: Tombamento de blocos e flexural. Assim, a ruptura por tombamento do tipo bloco-flexural pode ser considerada a forma mais comum presente neste tipo de mecanismo. Trabalhos utilizando o método de equilíbrio limite ou modelos físicos estudam a influência desta combinação, mas a literatura relata poucos trabalhos numéricos que possam ajudar na compreensão dos fenômenos envolvidos neste processo de ruptura. $\mathrm{O}$ presente trabalho procura modelar o mecanismo de ruptura por tombamento bloco-flexural através do método dos elementos discretos (DEM), utilizando o software PFC (Particle Flow Code). Em particular, procura-se avaliar as potencialidades do método para estudos deste tipo, utilizando um novo modelo de contato entre partículas e a calibração das propriedades elásticas do material sintético. Apresentam-se também detalhes da metodologia utilizada e exemplos de validação, incluindo comparações com soluções analíticas e semi-analíticas disponíveis na literatura.

\section{Palavras-chave}

Método dos Elementos Discretos; Estabilidade de taludes; Tombamento bloco-flexural; Mecânica das Rochas; Resistência à tração das rochas. 


\section{Abstract}

Elorrieta Agramonte, Fredy Alvaro; Vargas, Euripedes Jr. (Advisor); Figueiredo, Rodrigo Pelucci. Application of the Discrete Element Method for Modelling the Block-Flexural Toppling Mechanisms in Rock Slopes. Rio de Janeiro, 2014. 106p. MSc. Dissertation - Departamento de Engenharia Civil, Pontifícia Universidade Católica do Rio de Janeiro.

Joints exhibit an irregular and discontinuous behavior inside the rock mass. The spatial distribution complexity of these discontinuities causes the toppling failure occurs more often by a combination of two types of toppling phenomena: toppling of rock blocks and flexural toppling. Thus, the block-flexural toppling can be considered the most common when a toppling process is being developed in rock slopes. Analytical and physical models approach, were presented in order to study each process individually, but the literature reports few works that may help to understand the influence of the two processes together. The present work aims to represents the mechanism of block-flexural toppling through the discrete elements method (DEM) using the PFC (Particle Flow Code) software. In particular, the objective is to assess the potential of the method for studies of this type, using a new model of contact between particles and the elastic properties calibration of the synthetic material. In order to do that, the work shows the methodology details and validation examples, including comparisons with analytical and semi-analytical solutions that are available in the literature.

\section{Keywords}

Discrete element method; Rock slopes stability; Block-flexural toppling; Rock mechanics; Rock tensile strength. 


\section{Sumário}

1. Introdução 16

1.1. Definição do problema 16

$\begin{array}{ll}\text { 1.2. Objetivo do trabalho } & 17\end{array}$

$\begin{array}{ll}\text { 1.3. Estrutura do trabalho } & 17\end{array}$

2. Estudos de tombamento 19

2.1. Análise cinemática 22

2.2. Métodos analíticos 23

2.2.1. Solução analítica para tombamento de bloco 23

2.2.2. Equilíbrio limite para tombamento flexural 25

2.2.3. Equilíbrio limite para tombamento bloco-flexural 27

2.3. Modelos físicos 32

3. Método dos elementos discretos (DEM) 34

3.1. Código de Fluxo de Partícula (PFC) 34

3.1.1. Ciclo de cálculo no PFC 35

3.1.2. Modelo de contacto do tipo Flat-Joint 41

4. Calibração do material 48

4.1. Geração do material 48

4.2. Flexão em vigas 49

4.3. Resistência à tração da rocha 52

4.3.1. Ensaio de tração direta $\quad 54$

4.3.2. Ensaio Brasileiro $\quad 55$

4.3.3. Ensaio de flexão de quatro pontos 57

4.3.4. Ensaio de flexão de três pontos 58

4.4. Ensaio de corte direto em descontinuidades de rocha modeladas pelo modelo de contacto do tipo Smooth-Joint 62 
5. Modelagem de taludes em processos de tombamento $e$ comparação com métodos analíticos físicos e semi-analíticos

5.1. Analise do tombamento de um bloco sobre uma base inclinada

5.2. Problema do tombamento de blocos em uma base do tipo escada

5.3. Tombamento flexural pelo método de Aydan e Kawamoto 71

5.4. Tombamento flexural em modelos físicos 76

5.4.1. Modelagem numérica do talude físico 76

5.5. Tombamento bloco-flexural 80

5.5.1. Avaliação do talude com a interação das falhas simultaneamente 84

5.5.2. Tombamento bloco-flexural com famílias de falhas distribuídas aleatoriamente $\quad 87$

6. Conclusões e sugestões de trabalhos futuros 90

6.1. Conclusões 90

6.2. Sugestões para estudos futuros 94

Referencias Bibliográficas 96

A Cálculo analítico Aydan e Kawamoto 100

B Cálculo analítico Bloco-flexural, método Amini et al. 102 


\section{Lista de figuras}

Figura 2.1 - Modos primários de Toppling, (a) Tombamento de blocos contendo juntas ortogonais com grande espaçamento,

(b) Tombamento flexural, (c) Tombamento bloco-flexural, caracterizado por deslocamentos acumulados em colunas pseudocontínuas a traves de juntas ortogonais [24]

Figura 2.2 - Modos primários de Toppling, (a) Tombamentos por deslizamentos inferiores (slide-head-toppling), (b) Tombamentos por deslizamentos na base (slide base toppling), (c) Tombamentos por deslizamentos superiores (slide-toe-toppling, (d) Tombamentos por juntas de tensão (tension crack toppling); [24]

Figura 2.3 - Representação do processo de tombamento em formações com descontinuidades cataclinais [17]

Figura 2.4 - Estereograma com a representação dos limites geométricos para à Ocorrência do tombamento.

Figura 2.5 - Bloco em posição limite para o tombamento, [24]

Figura 2.6 - Condições cinemáticas para o deslizamento entre blocos o qual precede o tombamento; representação do talude e a direção da tensão principal, projeção estereográfica para a condição de tombamento [24]

Figura 2.7 - Modelo para o analise de equilíbrio limite para tombamento flexural em taludes [7]

Figura 2.8 - Idealização do tombamento bloco-flexural; Amini et al. [5].

Figura 3.1 - Representação do contato entre partículas (A-B) e parede partícula (W-b), Itasca [30]

Figura 3.2 - Representação geométrica do flat joint contact model [35]

Figura 3.3 - Velocidade das superfícies imaginárias do flat-joint no contato [35] 
Figura 3.4 - Cinemática do contato do tipo flat-joint mostrando a interface (azul) com deslocamentos relativos das superfícies (vermelho e verde) [35]

Figura 3.5 - "Gap" relativo ao deslocamento da superfície e a interface [35]

Figura 3.6 - Forças atuantes nas superfícies imaginárias e a sua segmentação [35]

Figura 3.7 - Tensões normais na interface para superfícies compostas por quatro segmentos [35]

Figura 3.8 - Lei de Força-Deslocamento para o segmento desligado (a) tensão normal no centroide do segmento versus o "gap" (g), (b) tensão no centroide do segmento versus o deslocamento relativo, (c) envolvente de ruptura [35] Figura 3.9 - Lei de Força-Deslocamento para o segmento ligado (a) tensão normal no centroide do segmento versus o gap (g), (b) tensão cisalhante no centroide do segmento versus o deslocamento relativo, (c) envolvente de ruptura [35]

Figura 4.1 - Gerado de partículas.

Figura 4.2 - Flexão da viga pelo carregamento pontual no extremo, pontos de monitoramento, tensões de tração e compressão geradas.

Figura 4.3 - Comparativo na flexão, calculado pelo PFC2D vs a fórmula Analítica de Timoshenko

Figura 4.4 - Comparativo na flexão, calculado pelo PFC2D vs a fórmula analítica de Timoshenko

Figura 4.5 - Comparativo do erro na flexão em diferentes pontos das vigas; Espécimes 1 e 2 parallel-bond, Espécime 3 contact bond mais parallel bond, Espécimes 4 e 5 at-joint contact model

Figura 4.6 - Corpo de prova submetido à tração direta e círculos de medição

Figura 4.7 - Diferentes espécimes ensaiados a tração direta e localização das fraturas. 
Figura 4.8 - Ensaio Brasileiro, representação das rupturas do modelo de contato do tipo flat-joint por cisalhamento e tração

Figura 4.9 - Ensaio de flexão quatro pontos

Figura 4.10 - Diferentes espécimes ensaiados a flexão de

quatro pontos e o posicionamento das fraturas.

Figura 4.11 - Ensaio de tração direta, Hawkes and Mellor (1970).

Figura 4.12 - Diferentes espécimes ensaiados em flexão de três pontos e posicionamento das fraturas.

Figura 4.13 - Valores de resistência pico de diferentes ensaios à tração.

Figura 4.14 - Comparação curvas tensão deformação.

Figura 4.15 - Ensaio de corte direto na descontinuidade de rocha.

Figura 4.16 - Criação de um novo contato do tipo "lineal" durante o ensaio de corte direto

Figura 4.17 - Comparação entre o modelamento convencional da fratura vs o modelamento com o código de correção a diferentes tensões normais aplicadas (1.0, 0.8 e $0.6 \mathrm{KPa})$.

Figura 5.1 - Bloco exposto ao tombamento.

Figura 5.2 - Blocos avaliados contra o tombamento. a. $\theta=32^{\circ}$;

b. $\theta=38,65^{\circ}$; c. $\theta=31^{\circ}$

Figura 5.3 - Curvas do deslocamento do vértice superior de cada bloco na coordenada " $X$ " versus o time step.

Figura 5.4 - Tombamento de bloco em uma base inclinada do tipo escada Goodman e Bray [24].

Figura 5.5 - Modelamento no PFC do tombamendo de bloco em uma base do tipo escada Goodman e Bray [24].

Figura 5.6 - Velocidades do bloco no pé do talude com diferentes ângulos de atrito avaliados no PFC2D, para o problema de toppling Goodman e Bray [24].

Figura 5.7 - Modelamento do tombamento flexural segundo Aydan e Kawamoto [7], considerando as condições de contorno. 
Figura 5.8 - Deformação apresentada no topo do talude vs o time step para diferentes valores de rigidezes.

Figura 5.9 - Avaliação na estabilidade do modelo numérico com diferentes valores de rigidez nas fraturas.

Figura 5.10 - Modelo numérico, condições de contorno e condições iniciais, talude físico estudado por Adhikary et al. [1]

Figura 5.11 - Deslocamentos horizontais do ponto "A" da simulação numérica do talude do trabalho de Adhikary et al. [1] para diferentes valores de rigidez nas descontinuidades.

Figura 5.12 - Comparação entre as superfícies de fratura do modelo físico e o modelo numérico. Apresentação dos pontos de monitoramento "A" e "B".

Figura 5.13 - Tensões de tração (vermelha) e compressão (preta) nas colunas que conformam o talude, zona de flexão onde é gerada a superfície de fratura.

Figura 5.14 - Talude com descontinuidade secundária com característica não contínua, para a modelagem do tombamento bloco-flexural.

Figura 5.16 - Ruptura do talude A por tombamento blocoflexural com descontinuidade não persistente a $18^{\circ}$ de mergulho, fratura da última coluna no pé do talude.

Figura 5.15 - Mudança da locação do ponto de aplicação da força intercolunar para o cálculo analítico do tombamento bloco-flexural (para Amini et al. [5]).

Figura 5.17 - Ruptura do talude B por tombamento blocoflexural, começo da fratura na antepenúltima coluna.

Figura 5.18 - Ruptura dos taludes com a interação das falhas simultaneamente, fig. (a) talude C com falhas de $18^{\circ}$ e $32^{\circ}$ graus de mergulho; fig. (b) talude $\mathrm{D}$ com falhas de $18^{\circ} ; 23^{\circ} \mathrm{e}$ $32^{\circ}$ graus de mergulho.

Figura 5.19 - Deslocamentos do topo do talude para ação das descontinuidades secundárias interagindo simultaneamente.

Figura 5.20 - Evolução do falhamento à tração em contactos do tipo flat-joint nos taludes baixo o tombamento bloco-flexural. 
Figura 5.21 - Tombamento bloco-flexural com diversas famílias de falhas, estado inicial a $0 \mathrm{~g}$ 's e no estado final a $15 \mathrm{~g}$ 's.

Figura 5.22 - Tombamento bloco-flexural com diversas famílias de falhas aleatórias.

Figura A.1 - Cálculo analítico tombamento flexural pelo método de Aydan e Kawamoto

Figura B.1 - Cálculo analítico do tombamento bloco-flexural no talude A; Amini et al.(2010).

Figura B.2 - Cálculo analítico da estabilidade do talude A considerando as mudanças dos pontos de aplicação das forças.

Figura B.3 - Cálculo analítico do tombamento bloco-flexural no talude B; Amini et al.(2010).

Figura B.4 - Cálculo analítico da estabilidade do talude B considerando as mudanças dos pontos de aplicação das forças.

Figura B.5 - Cálculo analítico do tombamento bloco-flexural no talude B com a re-definição da "coluna chave" e considerando a mudança dos pontos de aplicação das forças 


\section{Lista de tabelas}

Tabela 4.1 Macro-parâmetros das vigas sometidas a flexão por carregamento pontual no extremo.

Tabela 4.2 Micro-propriedades dos modelos de contato empregados para o corpo de prova submetido a corte direto.

Tabela 4.3 Macro-propriedades do material para o ensaio de corte direto.

Tabela 5.1 Propriedades do material avaliado no processo de tombamento flexural Aydan e Kawamoto [7].

Tabela 5.2 Propriedades do material avaliado e o talude sujeito a tombamento flexural Adhikary et al. [1]

Tabela 5.3 Micro-propriedades dos modelos de contato

empregados na calibração do material do ensaio físico. 


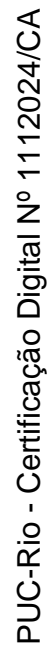

Porque não existe experiência no presente como tal, se antes não foi refletida.

Sören Kierkegaard. 